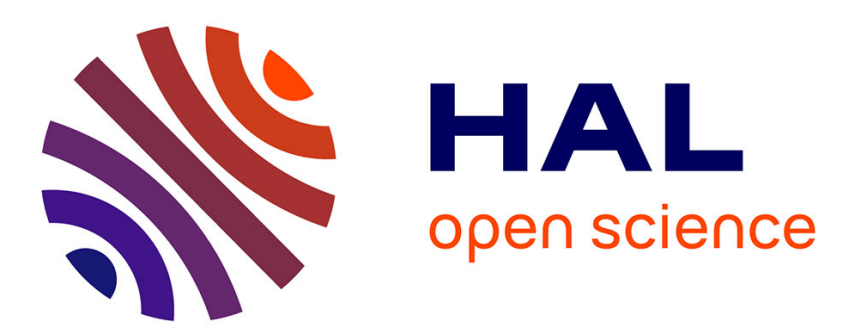

\title{
Tunnelling investigation of the phonon spectrum of superconducting Be implications for an eventual enhancement of Tc
}

\author{
A. Léger, J. Klein, S. de Cheveigne, M. Belin, Daniel Defourneau
}

\section{To cite this version:}

A. Léger, J. Klein, S. de Cheveigne, M. Belin, Daniel Defourneau. Tunnelling investigation of the phonon spectrum of superconducting Be implications for an eventual enhancement of Tc. Journal de Physique Lettres, 1975, 36 (12), pp.301-304. 10.1051/jphyslet:019750036012030100 . jpa-00231214

HAL Id: jpa-00231214

https://hal.science/jpa-00231214

Submitted on 1 Jan 1975

HAL is a multi-disciplinary open access archive for the deposit and dissemination of scientific research documents, whether they are published or not. The documents may come from teaching and research institutions in France or abroad, or from public or private research centers.
L'archive ouverte pluridisciplinaire HAL, est destinée au dépôt et à la diffusion de documents scientifiques de niveau recherche, publiés ou non, émanant des établissements d'enseignement et de recherche français ou étrangers, des laboratoires publics ou privés. 


\title{
TUNNELLING INVESTIGATION OF THE PHONON SPECTRUM OF SUPERCONDUCTING Be IMPLICATIONS FOR AN EVENTUAL ENHANCEMENT OF $T_{\mathrm{c}}(*)$
}

\author{
A. LÉGER, J. KLEIN, S. DE CHEVEIGNE, M. BELIN and D. DEFOURNEAU
}

Groupe de Physique des Solides de l'Ecole Normale Supérieure (**), Tour 23, 2, place Jussieu, 75221 Paris Cedex 05, France

(Reçu le 13 juin 1975, accepté le 10 septembre 1975)

\begin{abstract}
Résumé. - Le béryllium est un supraconducteur tout particulièrement intéressant car la théorie situe la limite supérieure de sa $T_{\mathrm{c}}$ à $140 \mathrm{~K}$. Partant de la phase du Be dont la $T_{\mathrm{c}}$ est déjà de $9,5 \mathrm{~K}$, nous discutons la possibilité d'augmenter cette température critique. Une étude par effet tunnel de cette phase nous conduit à penser qu'il s'agit bien d'un supraconducteur à couplage faible $(\lambda<0,6)$ qui est donc susceptible de présenter des élévations importantes de sa $T_{\mathrm{c}}$.
\end{abstract}

\begin{abstract}
Beryllium is an exciting superconductor in that the theoretical upper limit for its $T_{\mathrm{c}}$ is $140 \mathrm{~K}$. We discuss here the possibility of increasing the critical temperature of the vapour quenched phase whose $T_{\mathrm{c}}$ is already $9.5 \mathrm{~K}$. Tunnelling into films of this phase indicates that it is a weak coupling superconductor $(\lambda<0.6)$. Consequently, its $T_{\mathrm{c}}$ could be greatly enhanced, although experimental attemps have failed up to now.
\end{abstract}

1. Can one expect an increase for the $T_{\mathrm{c}}$ of superconducting Be ? - Theories based on an electronphonon interaction $\left({ }^{1}\right)$ lead to the conclusion that the upper limit of the critical temperature $T_{\mathrm{c}}$ of a superconductor is around $\theta / 10$, where $\theta$ is its Debye temperature. Beryllium is therefore a fascinating material as its Debye temperature is $1400 \mathrm{~K}$, far above that of most other metals. It should be emphasized that this straight forward conclusion has somehow escaped notice in the literature on high $T_{\mathrm{c}}$ superconductors, probably because the case of $\mathrm{Be}$ was not discussed in the famous paper on the maximum critical temperature by Mc-Millan [2].

The ordinary $\alpha$ phase of Be has a very low $T_{\mathrm{c}}$ $(0.026 \mathrm{~K})$, but there is another phase, perhaps amorphous [3] (here after called $\gamma \mathrm{Be}$ ) which is superconducting at $9.5 \mathrm{~K}$, obtained by cryogenic condensation of Be vapour. In this paper, we shall discuss the possibility of increasing the $T_{\mathrm{c}}$ of $\mathrm{Be}$ in this phase.

The question of the enhancement of the $T_{c}$ of

(*) Work supported, in part, by the D.R.M.E. contract $\mathbf{n}^{0} 73 / 683$.

$\left({ }^{* *}\right)$ Laboratory associated with the C.N.R.S. and the University of Paris VII.

( ${ }^{1}$ If some additional excitonic mechanism is invoked, a high Debye temperature material is still very interesting because the prefactor in the expression of $T_{\mathrm{c}}$ versus the coupling parameters [1] remains proportional to $\theta$. superconductors has received considered attention during the last few years. It is known that when a superconductor is submitted to an appropriate treatment (thin, or cold, film deposition [4], quenching with another material [5]), its $T_{\mathrm{c}}$ may be greatly enhanced (Al, Mo, Sn...) or it may remain the same and even decrease $(\mathrm{Pb}, \mathrm{Hg}$...). Since the paper [2] by Mc-Millan, this situation is reasonably well understood. McMillan found that the critical temperature is given by :

$$
T_{\mathrm{c}}=\frac{\langle\omega\rangle}{1.20} \cdot \exp \frac{-1.04(1+\lambda)}{\lambda-\mu^{+}-0.62 \lambda \mu^{+}}
$$

where $\lambda$ is the electron-phonon coupling parameter (which also gives the increase of the electronic effective mass due to phonons), $\mu^{+}$is a constant ( 0.10 to $0.13)$, and $\langle\omega\rangle$ is an average of the phonon frequency defined with a weight function $\alpha^{2}(\omega) F(\omega)$ :

$$
\langle(t)\rangle=\frac{\int \mathrm{d} \omega \alpha^{2}(\omega) F(\omega)}{\int \mathrm{d} \omega \frac{1}{\omega} \alpha^{2}(\omega) F(\omega)} .
$$

The plot of $T_{\mathrm{c}}$ as a function of $\lambda$ in figure 1 shows that depending on whether a metal is a weak coupling superconductor $(\lambda<0.5)$ or a strong coupling one $(\lambda>1)$, its $T_{\mathrm{c}}$ will or will not be very sensitive to 


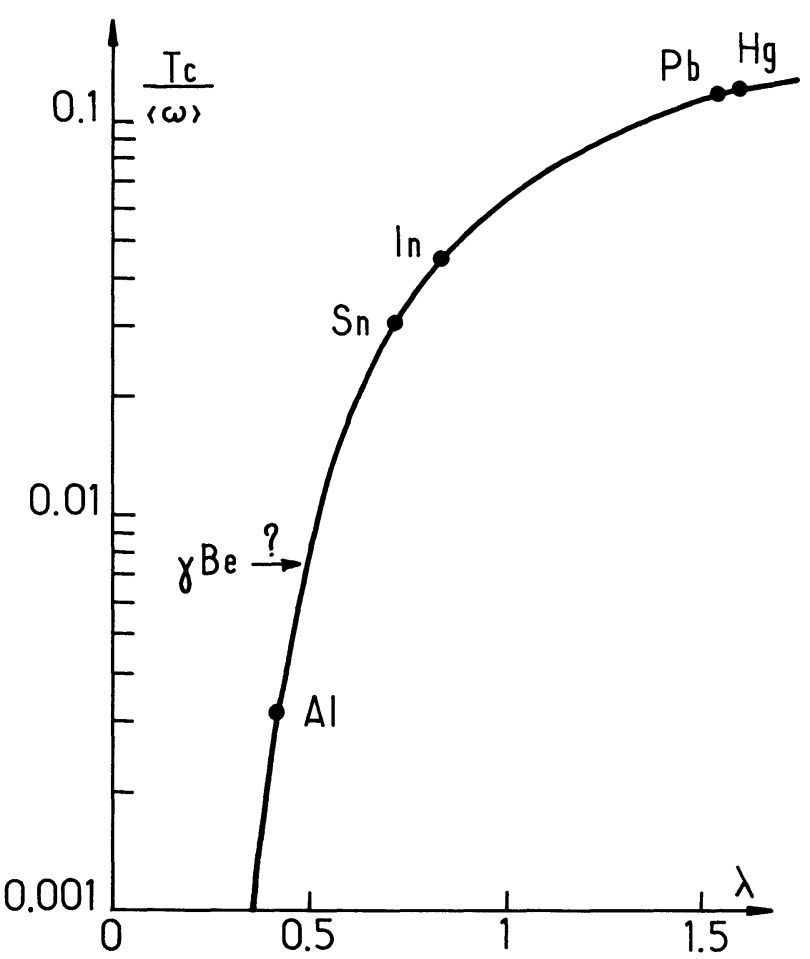

FIG. 1. $-T_{\mathrm{c}} /\langle\omega\rangle$ versus $\lambda$ for $\mu^{*}=0.12$. The position of $\gamma \mathrm{Be}$ on the curve assumes $\langle\omega\rangle$ to be $\theta / 1.2$ with the same Debye temperature as for the ordinary $\alpha$ phase of Be.

small modincations of its coupling parameter. One can find in the literature $[2,6,7,8]$ some discussion of the dependence of $\lambda$ on the electron and phonon properties of the metal, and the corresponding possibilities of modification by metallurgical treatment. The following distinction appears to be clear : superconductors with small $\lambda$ can present strong $T_{\mathrm{c}}$ enhancement, those with large $\lambda$ can present only a very slight one.

As far as $\gamma \mathrm{Be}$ is concerned, it is necessary to know its position on the curve of figure 1 in order to determine whether its $T_{\mathrm{c}}$ can be increased or not. If the phonon spectrum of $\gamma \mathrm{Be}$ was roughly the same as that of $\alpha \mathrm{Be}$ and if the weight function $\alpha^{2}(\omega) F(\omega)$ was almost proportional to the phonon density of states $F(\omega)$, one would have :

$$
\langle\omega\rangle \simeq \theta / 1.2 \text { with } \theta \simeq 1400 \mathrm{~K},
$$

then $T_{\mathrm{c}} /\langle\omega\rangle \simeq 0.008$ and $\lambda \sim 0.49$. Under these assumptions, $\gamma \mathrm{Be}$ would be a weak coupling superconductor and its $T_{\mathrm{c}}$ could be largely enhanced $\left({ }^{2}\right)$.

There are reports of some experimental attempts to increase the critical temperature of $\gamma \mathrm{Be}$. Alekseevskii et al. [9] have made coevaporations of $\mathrm{Be}$ and $\mathrm{KCl}$ or $\mathrm{Zn}$ etioporphyrin on $4.2 \mathrm{~K}$ substrates and found $T_{\mathrm{c}}$ less than $10.5 \mathrm{~K}$. Comberg et al. [11] have made the

$\left({ }^{2}\right)$ If the (optimistic) hypothesis is made that one can make the same relative change of $\langle\omega\rangle$ as in the case of $\mathrm{Al}$ whose $T_{\mathrm{c}}$ goes from $1.2 \mathrm{~K}$ to $6.5 \mathrm{~K}$ [5], the predicted critical temperature for $\gamma \mathrm{Be}$ is $35 \mathrm{~K}$, which is challenging ! same experiments with Ge but did not succeed in increasing the $T_{\mathrm{c}}$. We have also made codepositions of $\mathrm{Be} / \mathrm{Ge}, \mathrm{Be} / \mathrm{SiO}, \mathrm{Be} / \mathrm{Be}$ oxide with no better results.

These experiments are disappointing and even somewhat surprising, and the question is raised as to whether those attempts were unsuccessful in increasing $\lambda$ or whether the above discussion is simply not correct. For instance, one possibility might be that $\gamma \mathrm{Be}$ is, in fact, a strong coupling material. This would mean that $\langle\omega\rangle$ is far smaller than expected, because of an under-estimate of the low frequency modes. An attempt can be made to check this hypothesis by tunnelling experiments.

2. Tunnelling into Be films. - The first test required to determine whether a superconductor is a strong coupling one or not is to measure the $2 \Delta / k T_{\mathrm{c}}$ ratio. The experiment has been performed by Alekseevskii et al. [10], Combert et al. and Granqvist et al. [11], who found 3.5 to $3.7,3.7$ and 3.45 to 3.6 respectively. If we assume the relation between $2 \Delta / k T_{\mathrm{c}}$ and $T_{\mathrm{c}} /\langle\omega\rangle$ to be that of Geilikman and Kresin [12] :

$$
\frac{2 \Delta}{k T_{c}} \simeq 3.52\left[1+5.3\left(\frac{T_{c}}{\langle\omega\rangle}\right)^{2} \log \frac{\langle\omega\rangle}{T_{c}}\right]
$$

the corresponding values of $\lambda$ are $0-0.95,0.95,0-0.76$. Those experiments point to weak coupling but are clearly not sufficiently precise.

The second test consists in studying the phonon structure of the tunnelling characteristics and trying to deduce $\lambda$. Such experiments are reported here :

2.1 EXPERIMENTAL PROCEDURE. - Al-oxide-Be junctions were made by room temperature evaporation and oxidation of an $\mathrm{Al}$ film, and evaporation of $\mathrm{Be}$ at room temperature $(\alpha \mathrm{Be})$ or at $4.2 \mathrm{~K}(\gamma \mathrm{Be})$. The junctions were in the range $100 \Omega-10 \mathrm{k} \Omega$ and derivatives of the tunnelling curves were taken by standard techniques [13].

In order to obtain $\gamma \mathrm{Be}$ in the normal state, we had to perform measurements above $10 \mathrm{~K}$ because it is a high field superconductor and it could not be driven to the normal state by available magnetic fields, the corresponding thermal smearing was a limitation for the resolution of the diode characteristics.

2.2 PhONONS OF $\alpha$ Be AND $\gamma$ Be (IN THE NORMAL STATE). - In a first experiment, we have tried to compare the phonon spectrum of $\gamma \mathrm{Be}$ to that of ordinary $\alpha$ Be by inelastic tunnelling spectroscopy [14] on films of the two phases, in the normal state. Second derivative characteristics of the corresponding $\mathrm{Al}-\mathrm{Be}$ junctions are reported in figure 2. A small bump can be seen at $35 \mathrm{mV}$ corresponding to the longitudinal phonon of the $\mathrm{Al}$ electrode. Another bump is observed with both types of $\mathrm{Be}$ in the range $65-85 \mathrm{mV}$. This structure is probably due to the phonons of Be because it occurs at the energy of the high frequency peak of the phonon spectrum of $\alpha \mathrm{Be}$ as deduced from neutron 


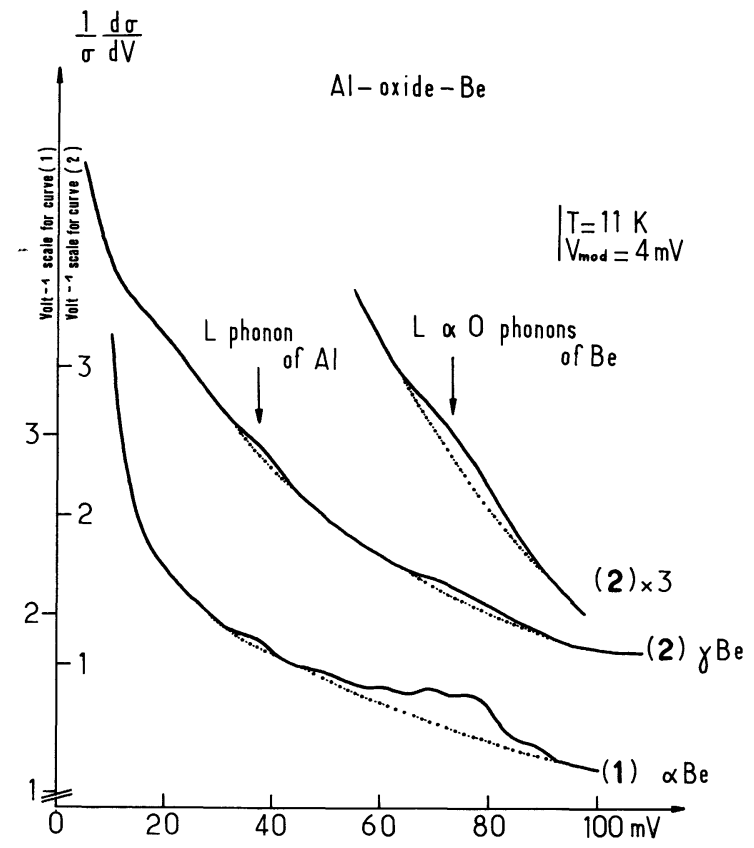

Fig. 2. - Second derivative characteristic of tunnel junctions $\mathrm{Al}-\mathrm{Be}$ (Be being in the normal state) : (1) with $\alpha \mathrm{Be}$, obtained by $300 \mathrm{~K}$ condensation of the metal vapour; (2) with $\gamma \mathrm{Be}$, obtained by $4.2 \mathrm{~K}$ condensation. The high energy phonons of $\mathrm{Be}$ are observed in both cases at approximately the same energy, but with a stronger intensity for $\alpha \mathrm{Be}$.

scattering experiments $(73 \mathrm{mV})$. The interesting point is that this bump occurs at the same energy for the two phases of $\mathrm{Be}\left({ }^{3}\right)$.

Clearly, we have not obtained the whole phonon spectrum of $\mathrm{Be}$. We do not see the low frequency region, probably because the coupling with those modes is weaker, but this experiment can be considered as an indication that the phonon spectra of the two phases have some similarities, what supports the hypothesis of relation (2). The next experiment provides more important (and precise) data.

\subsection{TUNNELLING INTO NORMAL AND SUPERCONDUCT-} ING $\gamma$ Be. - Tunnelling into $\gamma \mathrm{Be}$ in the superconducting state has already been performed see ref. [11] and it was reported that no reproducible phonon structure could be observed. Such structures however are supposed to be small (of the order of $T_{\mathrm{c}}^{2} /\langle\omega\rangle^{2}$ ) and the authors did not report the sensitivity of their measurements. If one wants to deduce a value of $\lambda$, a quantitative estimate is required. We therefore tried to reproduce the experiment and thus to measure this superconducting phonon structure.

Figure 3 reports the second derivative $\frac{1}{\sigma} \frac{\mathrm{d} \sigma}{\mathrm{d} V}$ cha-

$\left({ }^{3}\right)$ However its amplitude is about 5 times greater for cristalline $\alpha \mathrm{Be}$ than for $\gamma \mathrm{Be}$ but this may be due to the nature of the oxide-Be interfaces : the theory of tunnelling in normal metals [15] has shown that the amplitude of phonon structure strongly depends upon the interface structure and this may be quite different for the two junctions.
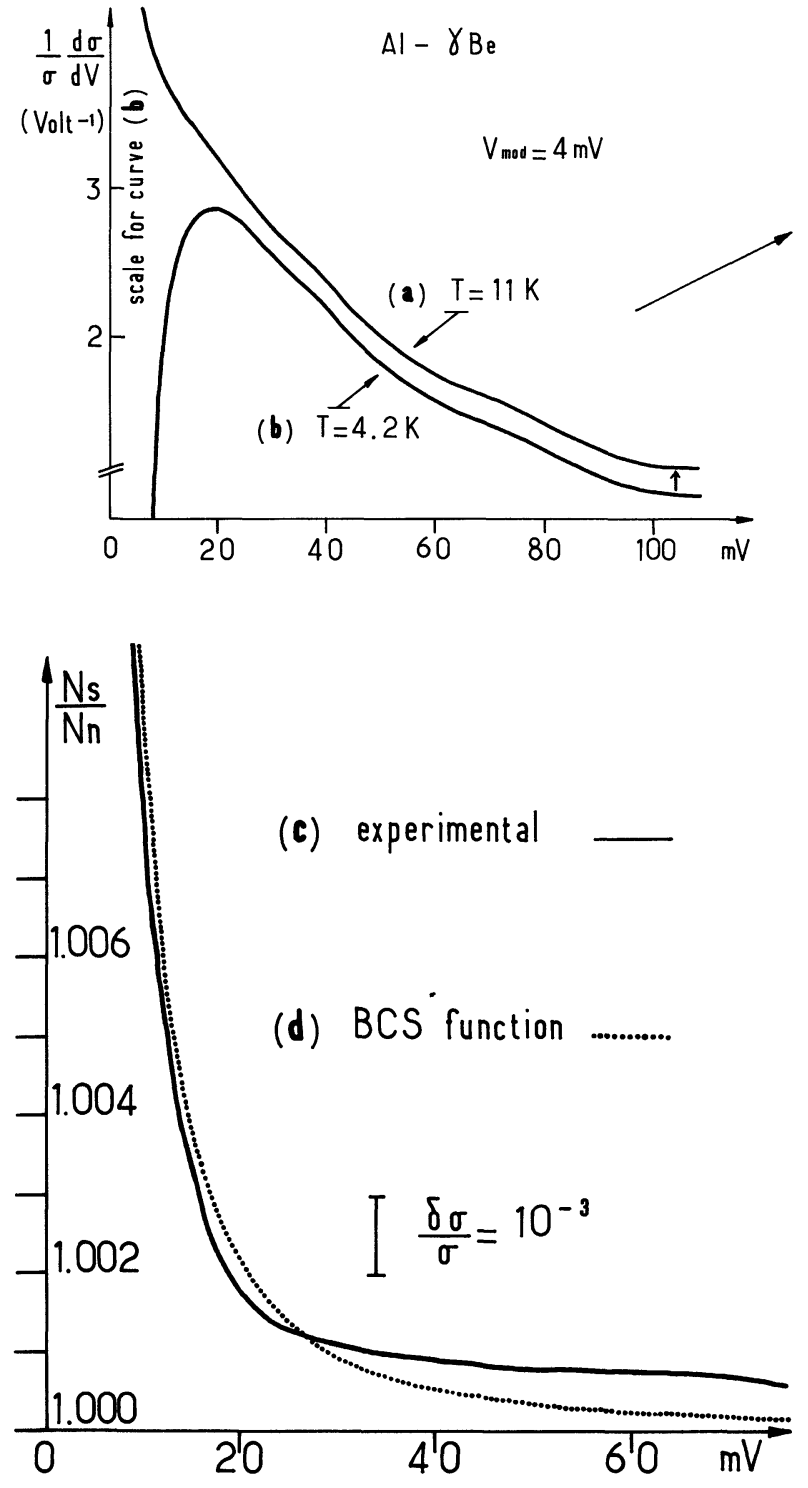

Fig. 3. - Tunnelling into $\gamma$ Be : (a) Normal state; (b) Superconducting state (vertically shifted for clarity); (c) Deduced superconducting density of states; (d) BCS density of states. The difference between curve (c) and (d) is estimated to be less than $10^{-3}$, and this allows the evaluation of an uper limit for $\lambda$ which is 0.6 .

racteristic of $\mathrm{Al}-\gamma \mathrm{Be}$ junction when $\gamma \mathrm{Be}$ is in the normal (a) or in the superconducting state (b). Curves are shifted vertically for clarity. Both curves present a general background which is apparent because of the expanded scale but corresponds to rather weak zero bias anomaly of the first derivative. At low energy the superconducting gap makes curve (b) strongly deviate from curve (a). It should be mentioned that the ratio of the junction resistances for high voltage and zero voltage indicates that at least $95 \%$ of the electrons cross the junction by tunnelling.

In order to obtain quantitative data, one must use the first derivative. An integration of the (accurately) measured difference between curves (a) and (b) gives the ratio of the conductances in the superconducting and the normal states $\left(\sigma_{\mathrm{s}} / \sigma_{\mathrm{n}}\right)$ as : 


$$
\begin{aligned}
& \int_{V}^{\infty}\left(\frac{1}{\sigma_{\mathrm{n}}} \frac{\mathrm{d} \sigma_{\mathrm{n}}}{\mathrm{d} V}-\frac{1}{\sigma_{\mathrm{s}}} \frac{\mathrm{d} \sigma_{\mathrm{s}}}{\mathrm{d} V}\right) \mathrm{d} V=\log \frac{\sigma_{\mathrm{n}}}{\sigma_{\mathrm{s}}}(V)- \\
& -\log \frac{\sigma_{\mathrm{n}}}{\sigma_{\mathrm{s}}}(\infty)=\frac{\sigma_{\mathrm{s}}}{\sigma_{\mathrm{n}}}(V)-1+O\left[\frac{\sigma_{\mathrm{s}}}{\sigma_{\mathrm{n}}}(V)-1\right]^{2}
\end{aligned}
$$

provided that $V$ is in the voltage range where $\sigma_{\mathrm{s}} / \sigma_{\mathrm{n}}$ is close to $1\left(V>8 \mathrm{mV}\right.$ for a $10^{-4}$ precision). In practice, the upper limit of the integration is $100 \mathrm{mV}$ as our characteristics in the normal and superconducting states are indistinguishable above that voltage. Curve (c) reports the superconducting density of states which is obtained $\left(N_{\mathrm{s}} / N_{\mathrm{n}}=\sigma_{\mathrm{s}} / \sigma_{\mathrm{n}}\right)$. The precision of this determination is estimated to be of a few $10^{-4}$. For comparison, the BCS density of states is also plotted (curve (d)). It appears that the $\gamma$ Be density of states deviates from the BCS function by less than $1 \times 10^{-3}$ in the voltage range $(8-100 \mathrm{mV})$.

It would be interesting to make a deconvolution of the gap equation [16] and deduce $\alpha^{2}(\omega) F(\omega)$. Unfortunately this has not been possible because the precision which. would be necessary is about $10^{-5}$ which we have been unable to obtain. Our experimental incertitude has two origins : the thermal broadening that does not allow a good determination of the normal curve (plotted at $11 \mathrm{~K}$ ) and a small shift in the measured voltages when the Be film goes from the non-resistive state to the resistive one. This is due to the fact that the resistance of the part of the Be film that forms the electrode of the junction is not negligible $(\sim 1 \Omega)$ compared to the junction resistance (1-10 k $\Omega)$.

However, using only the upper limit for the deviations of the density of states from the BCS theory $\left(\delta \sigma / \sigma<10^{-3}\right)$ we can calculate an upper limit for $\lambda$. A theoretical evaluation of those deviations can be made by using an approximate resolution of the
Eliashberg equations and the strong coupling expression of the tunnelling current in superconductors [16] We found :

$$
\frac{\delta \sigma}{\sigma} \simeq \frac{1}{2}\left[\frac{\Delta}{\langle\omega\rangle} \log \frac{2\langle\omega\rangle}{\Delta}\right]^{2} \cdot\left(\frac{\lambda}{1+\lambda}\right)^{2}
$$

this expression, that varies approximately as $T_{\mathrm{c}}^{2} /\langle\omega\rangle^{2}$, has been tested on several superconductors $(\mathrm{Pb}, \mathrm{In}, \mathrm{Ta})$ and it fits the experimental values correctly. Thus, from eq. (4) and (1) we can deduce the limitation for $\lambda$ :

$$
\lambda<0.6 \text {. }
$$

3. Conclusion. - The value of 0.6 obtained for the upper limit of the coupling parameter $\lambda$ of $\gamma \mathrm{Be}$ implies that the metal is a weak coupling superconductor. Therefore, although experimental attempts have failed up to now, its critical temperature should in fact present a large enhancement if one could increase $\lambda$. We believe that cryogenic condensation already gives a somewhat optimized $\lambda$ and that the difficulty is in achieving a further increase. Presently, we are planning to make ion implantation in this $\gamma \mathrm{Be}$ as this is another approach to obtain $T_{\mathrm{c}}$ enhancement. It is attractive since it has given spectacular results in the (very specific) case of Pd-H [17]. Recently, in collaboration with $\mathrm{H}$. Bernas's group and $\mathrm{F}$. Meunier, we have also obtained [18], by this method, promising $T_{\mathrm{c}}$ increase for $\mathrm{Al}$ which is the standard weak coupling superconductor.

Whether or not, one will succeed to raise the $\lambda$ of $\gamma \mathrm{Be}$ is an open question which is worth investigating as it is our opinion that Beryllium is one of the very few systems where a critical temperature above $30 \mathrm{~K}$ might be expected in the distant future (A 15 materials, for instance, being limited by their rather low Debye temperature).

\section{References}

[1] Ginzburg, V. L., Annu. Rev. Mater. Sci. 2 (1972) 683, ed. by R. A. Huggins, Stanford University, U.S.A.

[2] MC-Millan, W. L., Phys. Rev. 167 (1968) 331.

Dynes, R. C., Solid State Commun. 10 (1972) 615.

[3] Glover III, R. E., J. Low Temp. Phys. 8 (1971) 519; but new and preliminary experiments by GLOVER III, R.E., seem to point to the opposite conclusion (private communication).

[4] HiLsch, R., Non Crystalline Solids (ed. by V. D. Freschette, J. Wiley, N.Y.) 1958.

Strongin, M., Kammerer, O. F., Crow, J. E., Parks, R. D., Douglas, D. M., Jensen, M. A., Phys. Rev. Lett. 21 (1968) 1320.

[5] Fontaine, A. and Meunier, F., Phys. Kondens. Mater. 14 (1972) 119.

Abeles, B. and Hanak, J. J., Phys. Lett. 34A (1971) 165.

Tsuei, C. C. and Johnson, W. L., Phys. Rev. B 9 (1974) 4742.

[6] Benneman, K. H., J. Physique Colloq. 35 (1974) C4-305.

[7] Klein, J. and LéGer, A., Phys. Lett. $28 A$ (1968) 134.

Hauser, J. J., Phys. Rev. B 3 (1971) 1611.

[8] Chen, T. T., Chen, J. T., Leslie, J. D. and Smith, Phys. Rev. Lett. 22 (1969) 526.
[9] AlekseevskiI, N. E., Tsebro, V. I. and Filippovich, E. I., JETP Lett. 13 (1971) 174.

[10] Alekseevskit, N. E. and Tsebro, V. I., J. Low Temp. Phys. 4 (1971) 679.

[11] Granqvist, C. G. and Claeson, Z. Phys. B 20 (1975) 13.

Comberg, A., Ewert, S. and WuHL, H., Z. Phys. B 20 (1975) 165.

[12] Geilikman, B. T. and Kresin, V., P.S.S. 7 (1965) 3297.

[13] See for instance : AdLeR, J. G. and JACKsON, J. E., Rev. Sci. Instrum. 37 (1966) 1049.

KLein, J., LéGER, A. and Delmas, B. (to be published in Revue Phys. Appl.).

[14] Klein, J., LéGer, A., Belin, M., Defourneau, D., SAngster, M. J. L., Phys. Rev. B 7 (1973) 2336.

[15] Caroli, C., Combescot, R., Nozières, P. and Saint-James, D., J. Phys. C 5 (1972) 21.

[16] MC-Millan, W. L., Rowell, J. M., Superconductivity (ed. R. D. Parks M. Dekker N. Y.) 1969 , p. 561.

[17] Buckel, W. and Stritzker, B., Phys. Lett. 43A (1973) 403

[18] Bernas, H. et al. (to be published). 